九州大学学術情報リポジトリ

Kyushu University Institutional Repository

\title{
The Effect of Transportation Disruptions on Cold Chain Sustainability
}

\section{Nurul Syafiqah Zulkefly}

Department of Mechanical \& Manufacturing Engineering, Faculty of Engineering and Built

Environment, Universiti Kebangsaan Malaysia

Hishamudd in, Hawa

Department of Mechanical \& Manufacturing Engineering, Faculty of Engineering and Built Environment, Universiti Kebangsaan Malaysia

Fat in Amrina A. Rashid

Department of Mechanical \& Manufacturing Engineering, Faculty of Engineering and Built Environment, Universiti Kebangsaan Malaysia

Razali, Noorhelyna

Department of Engineering Education, Faculty of Engineering and Built Environment, Universiti Kebangsaan Malaysia

他

https://doi.org/10.5109/4480702

出版情報 : Evergreen. 8 (2)，pp.262-270，2021-06. 九州大学グリーンテクノロジー研究教育センター バージョン：

権利関係 : 


\title{
The Effect of Transportation Disruptions on Cold Chain Sustainability
}

\author{
Nurul Syafiqah Zulkefly ${ }^{1}$, Hawa Hishamuddin ${ }^{* 1}$, Fatin Amrina A. Rashid ${ }^{1}$, \\ Noorhelyna Razali ${ }^{2}$, Nizaroyani Saibani ${ }^{1}$, Mohd Nizam Ab Rahman ${ }^{1}$ \\ ${ }^{1}$ Department of Mechanical \& Manufacturing Engineering, Faculty of Engineering and Built Environment, \\ Universiti Kebangsaan Malaysia, Selangor, Malaysia \\ ${ }^{2}$ Department of Engineering Education, Faculty of Engineering and Built Environment, \\ Universiti Kebangsaan Malaysia, Selangor, Malaysia
}

E-mail:*hawa7@ukm.edu.my

(Received December 31, 2020; Revised April 5, 2021; accepted April 14, 2021).

\begin{abstract}
Food and vaccine supply chains are a top priority in the cold chain sector as consumers are particularly concerned for the quality, safety, and environmental effects of these temperature sensitive products. Moreover, any disruptions to these supply chains will have adverse effects on the overall supply chain system and significantly increase the cost of recovery. Therefore, this study aimed to determine the optimum recovery cost for transportation disruptions in a cold chain system. A mathematical model was developed to analyse transportation disruption's effect, where the optimal recovery schedule consisting of production and shipment quantity decisions are determined by considering the economic and environmental impact. Particularly, the model quantifies the costs of carbon emissions from fuel consumption and the cooling system of the refrigerated truck. LINGO programming software was used to conduct a numerical analysis to determine the optimal recovery costs. Our findings indicate that truck load capacity was the main factor affecting total recovery costs as trucks carrying larger load capacities greatly reduced the frequency of shipment on a route thereby reducing the overall cost of carbon emissions.
\end{abstract}

Keywords: Cold Chain, Transportation disruptions, Carbon emissions, Optimum recovery cost

\section{Introduction}

Food supply chains consisting of farmers, suppliers, and production require careful distribution to ensure that food reaches the table of its consumers. The main factor that distinguishes fresh food supply chains from other supply chains is constant changes in quality; from the time it leaves the manufacturer and reaches the end consumer; due to the perishable nature of the product ${ }^{1}$. Therefore, the capacity of food supply chains depends on the ability of each of its components to cater to the ever-changing demands of consumers while efficiently taking into account the short shelf-life of the product ${ }^{2}$.

According to Sawik ${ }^{3}$, the current supply chain is more global and complex. As such, supply chains typically experience problems such as disruptions. Supply chain disruption gives a major impact and could lead to disastrous outcome in the whole supply chain system ${ }^{4}$. Transportation and logistics are also integral in food and vaccine supply chains. The costs of supply chain are influenced by logistics, making transportation a crucial part in every supply chain planning ${ }^{5}$. Not only that, logistics and transportation cause huge impact towards food supply chain that usually caters a broad geographical area, since the product needs to be delivered via a special type of transportation in a timely manner ${ }^{6}$. Transportation systems, such as cold chains for product supply and delivery, require certain temperature controls ${ }^{7}$. Therefore, any disruptions to the food supply chain will not only affect its overall conservation but increase food demand globally. Food supply disruptions may occur as a result of natural disasters, economic crises, and shipping or production mishaps. The three most common types of disruptions arise from production, supply, and transportation-related issues. A study by Pariazar et al. ${ }^{8)}$ found that any damages or disruptions in food chain operations can be overcome with careful management, thus, allowing food to be delivered to the consumer.

Transportation-related issues in cold chain supply affect the delivery process from its suppliers to its distributors. The quality of the products also relies heavily on the manufacturing, packaging, handling, and transportation processes $^{9)}$. Cai \& $\mathrm{Zhou}^{10)}$ state that public transport services are often utilised due to low shipping costs to external markets, however, frequent disruptions in delivery schedules often result in more problems. In the 
event of a disruption that delays the delivery of a product to the user, management attempts to mitigate the disruption by increasing production capacity. This increase in shipment frequency indirectly increases energy consumption and carbon emissions that adversely affect the environment ${ }^{11)}$. Moreover, timing as well as timely deliveries is of utmost importance in the cold chain supply industry as late deliveries not only impair product quality but increase the likelihood of damage.

As such, cold chain transportation; a special mode of logistics; was introduced to ensure that products are kept fresh at low temperatures throughout production, transportation, and sales to ensure product quality ${ }^{12)}$. Cold chain supply not only provides uninterrupted transport temperatures as well as upstream cooling and storage systems but suppliers who are capable of ensuring product quality and safety ${ }^{13)}$. Montoya et al. ${ }^{14)}$ claim that rising greenhouse gas prices are a major contributor to global warming; a growing and critical concern. Global warming causes serious impact towards the environment including the increase of sea levels and global temperature due to the presence of greenhouse gases (GHG) in the air ${ }^{15}$. Sosiati et al. ${ }^{16)}$ claimed that one of the leading factors for air pollution is the revolution of the automotive industry that involves the logistics and transportation systems in supply chain. Meanwhile, Shahriari et al. ${ }^{17)}$ stated that air pollution and fuel consumption can be reduced as the transportation usage is minimized. Thus, by optimising transportation decisions, the air pollution can be reduced by reducing the emission of carbon to the environment, simultaneously reducing the costs ${ }^{18-20)}$ of the supply chain.

Over the centuries, carbon dioxide (CO2) is known as the main contributor to greenhouse gas, in which refrigerants is one of the causes of carbon emission ${ }^{21)}$. As refrigerated vehicles or vehicles equipped with cooling systems are usually used to deliver food supplies, they have higher carbon footprints and emit other gasses that contribute to air pollution. Therefore, in the face of transportation disruptions, the disruption recovery cost increases as the number of deliveries increases to fulfill customer demand and backorders. This simultaneously increases carbon emissions which ultimately increases the overall carbon footprint. Therefore, the cold chain industry should be made aware of environmental protections and carbon emissions to reduce costs and, indirectly, learn about environmental impacts.

There are several studies in the literature that propose optimization models on cold chain management. Al Theeb et al. ${ }^{22)}$ formulated an optimization model to minimize the cost of transporting cold products that involve different types of vehicles, at the same time minimizing the penalty and inventory cost. Babagolzadeh et al. ${ }^{23)}$ proposed a model that minimize the overall operational costs and tax of carbon emissions in the cold supply chain considering the uncertain demand in this industry. Esmizadeh et al. ${ }^{24)}$ developed an optimization model for cold chain that involves several layers of supply chain network, in which every stage of the supply chain network is equipped with a refreshing procedure for the perishable goods, considering disruption such as uncertain demand and time frame for keeping freshness of the goods. Fang et al. ${ }^{25}$ formulated a model to optimize the cold chain for several types of imported agricultural goods with aims to minimize the total expenditure and carbon emissions. Garside ${ }^{26)}$ solved the cold chain problem by developing an optimization model that was able to minimize the total costs including energy cost, while considering the different characteristics of the transportation used. Hsu et al. ${ }^{27)}$ proposed the optimal distribution cycle for cold chain that considers a variety range of temperature needed to keep the fresh condition of the perishable products and seasonal demand from the end user. Wei et al. ${ }^{28)}$ formulated a model to minimize the total cost of a cold chain delivery system considering the different distances to deliver the goods to consumer location in which different types of vehicles were used for the short and long traveled distances. Ji et al. ${ }^{29)}$ designed a model to minimize the total transportation cost that include several layers of cold chain stages considering the time of freshness for the agricultural goods supplied within the cold chain network. While various studies were performed for optimising different aspects of cold chains, there has not been a study to date that integrates disruption and carbon emissions for the cold chain setting. Thus, this work intends to fill this research gap.

In this paper, a recovery model that takes into account carbon emissions from fuel consumption and refrigeration systems in a cold chain was developed to determine the optimum recovery cost for a production-inventory system. This model was based on a study conducted by Hishamuddin et al. ${ }^{30}$ who proposed a real-time rescheduling mechanism for transportation disruptions in a two-tier economic system of a supply chain. The purpose of our study was to determine the optimum number of production and shipment quantity orders to execute during the temporary recovery window in order to restore the original production schedule, as well as reduce the overall cold chain recovery and carbon emission costs. The main contribution of this study was the integration of the cost of carbon emissions from the refrigeration system of the cold chain trucks into the model.

This paper is organized as follows: section 2 presents the development of the mathematical model; Section 3 discusses the results of the analyses while section 4 concludes the paper.

\section{Model Formulation}

This section discusses the model development, which explains on the formulas and parameters used to form the mathematical model for the intended system. The system used in this study is a modified economic production quantity (EPQ) model. In the event of a disruption in the supply chain system, normal production is halted. After the disruption, recovery time is allocated to allow the 
revision of the

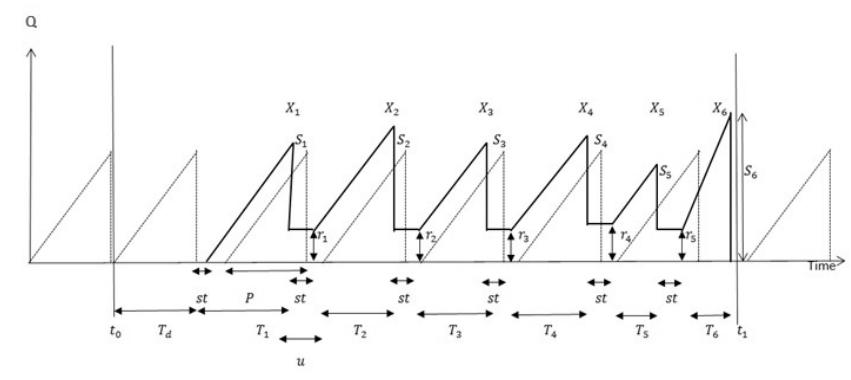

Fig. 1: Inventory Curve for the Problem.

production schedule to recover to the original schedule as quickly as possible, while minimising the total system costs. Fig. 1 shows the inventory curve of the problem. The dotted line resembles the original schedule, while the solid line is the new recovery schedule. This figure shows six recovery cycles $(n=6)$ where the decision variable $X_{i}$ is the production quantity, while $S_{i}$ is the shipment quantity.

Based on the constructed inventory curve, several parameters and notations were used to complement the inventory curve of this study. The parameters and notations used to develop the mathematical model for the cost function can be found in the nomenclature section at the end of this manuscript.

\subsection{Mathematical Representation}

The mathematical model constructed in this study is a constrained nonlinear programming problem and was developed based on the inventory curve presented in Fig. 1. The costs taken into account in this problem were setup cost (TC1), inventory holding cost (TC2), backorder cost (TC3), loss of sales cost (TC4), penalty cost (TC5), transportation cost (TC6), cooling cost (TC7), and total carbon cost (TC8). The setup, inventory and shortage costs are related to inventory management, particularly the EPQ system ${ }^{31}$, which was adopted for the single-stage inventory system considered in this study. These costs are standard cost components in inventory modeling that form the objective function, and have been modified to suit our problem under study. However, the unique extension of our model is the integration of the refrigeration and carbon emission costs from this source to the disruption recovery model. Applying the lot-for-lot policy, the production lot size $Q$ was formulated as follows:

$$
Q=\sqrt{\frac{2 A P}{H}}
$$

Setup cost (TC1) is the cost required to start the process, for instance the equipment or machinery to be used. The cost of inventory is the cost of preparation for cycle $A$ multiplied by the number of cycles $n$.

$$
T C 1=A^{*} n
$$

Inventory holding cost (TC2) is the annual cost of holding an inventory $H$ multiplied by the amount of inventory in holding during the recovery cycle corresponding to the area under the curve. This was calculated as follows:

$$
\begin{aligned}
& =H\left[\begin{array}{c}
\left.\frac{1}{2 P}\left(\sum_{i}^{n} X_{i}^{2}\right)+\frac{1}{2 P} X_{2}\left(X_{1}-S_{1}\right)+s_{t}\left(X_{1}-S_{1}\right)+\right] \\
\frac{1}{2 P} X_{3}\left(X_{2}-S_{2}\right)+s_{t}\left(X_{2}-S_{2}\right)+\cdots
\end{array}\right] \\
& = \\
& H\left[\begin{array}{c}
\frac{1}{2 P}\left(\sum_{i}^{n} X_{i}^{2}\right)+\left(X_{1}-S_{1}\right)\left(\frac{1}{2 P} X_{2}+s_{t}\right)+\left(X_{2}-S_{2}\right) \\
\quad+\left(\frac{1}{2 P} X_{3}+s_{t}\right)+\cdots
\end{array}\right] \\
& =H\left[\frac{1}{2 P}\left(\sum_{i}^{n} X_{i}^{2}\right)+\sum_{i=1}^{n-1}\left(X_{1}-S_{1}\right)\left(\frac{1}{2 P} X_{2}+s_{t}\right)\right]
\end{aligned}
$$

Backorder cost (TC3) was derived as follows:

$$
\begin{gathered}
=B\left[\begin{array}{c}
X_{1}\left(T_{d}+s t\right)+X_{2}\left(T_{d}+2 s t\right)+X_{3}\left(T_{d}+3 s t\right) \\
+X_{4}\left(T_{d}+4 s t\right) \\
+X_{5}\left(T_{d}+5 s t\right) \\
+X_{6}\left(T_{d}+6 s t\right)+\sum_{i=1}^{n} \frac{X_{i}^{2}}{P}-\frac{27 Q}{P}-21 u
\end{array}\right] \\
=B\left[\sum_{i=1}^{n} X_{i}\left(T_{d}+I s t\right)+\sum_{i=1}^{n} \frac{X_{i}^{2}}{P}-\frac{27 Q}{P}-21 u\right](4)
\end{gathered}
$$

Lost of sales cost (TC4) is the profit not received as the order cannot be fulfilled. Damaged products may also be included in this cost.

$$
T C 4=L\left(n Q-\sum_{i=1}^{n} X_{i}+Q(y)\right)
$$

Penalty cost (TC5) is the additional cost incurred when there is a change in the original schedule. The equation below was constructed as a function of cycles for recovery:

$$
\text { TC5 }=f\left(n^{2}\right)
$$

Transportation cost (TC6) is the number of shipments executed upon completion of the recovery period. Vehicle maintenance, fuel consumption, travel distance, and other factors are indirectly involved in transportation costs. 


$$
T C 6=C D \sum_{i=1}^{n}\left(\frac{S_{i^{*}} i}{q t}\right)
$$

Cooling costs (TC7) is the hourly cost of cooling each product throughout the delivery process multiplied by the time travelled to reach a specified destination. Therefore, the cooling cost for this model was as follows:

$$
T C 7=C r * t i
$$

Social carbon cost (TC8) is the cost of damage to the environment as a result of carbon emissions. Carbon emissions arise from fuel for the transmission and cooling systems of transport vehicles. The equation for this cost multiplies various variables, such as the number of cycles in the recovery window with the distance traveled by the vehicle, load capacity of the vehicle, total reductions in carbon dioxide emission, and carbon emissions from refrigeration devices. To calculate a vehicle's load capacity, the number of products in each vehicle is multiplied by the weight of one product. The social cost of carbon is shown in Equation 9:

$$
T C 8=(C O+W) *[n \times D i \times q t \times S C]
$$

The optimum cost is the sum of all the eight costs that had been built into the mathematical model and is depicted below.

$$
\begin{aligned}
& \text { Min TC }\left(X_{i} S_{i}, n\right) \\
& =\left(A^{*} n\right)+H\left[\frac{1}{2 P}\left(\sum_{i}^{n} X_{i}^{2}\right)+\sum_{i=1}^{n-1}\left(X_{1}-\right.\right. \\
& \left.\left.S_{1}\right)\left(\frac{1}{2 P} X_{2}+s_{t}\right)\right]+B\left[\sum_{i=1}^{n} X_{i}\left(T_{d}+I s t\right)+\right. \\
& \left.\sum_{i=1}^{n} \frac{X_{i}^{2}}{P}-\frac{27 Q}{P}-21 u\right]+L\left(n Q-\sum_{i=1}^{n} X_{i}+\right. \\
& Q(y))+f\left(n^{2}\right)+\left[\mathrm{CT} \sum_{i=1}^{n}\left(\frac{S_{i} * D i}{q t}\right)\right]+ \\
& \quad(C r * t i)+[(C O 2+W) *[n \times D i \times q t \times
\end{aligned}
$$

$S C]]$

Subject to the following constraints (11)-(16):

$$
\begin{aligned}
& \sum_{i=1}^{n} X_{i}=\sum_{i=1}^{n} S_{i} \\
& S_{n}=\mathrm{Q} \\
& S_{i} \leq \mathrm{qt} \\
& \sum_{i=1}^{n} X_{i} \geq m T D-\left(n Q-\sum_{i=1}^{n} X_{i}+Q(y)\right) \\
& \sum_{i=1}^{n} X_{i}=P *\left(n T-n s t-T_{d}\right)
\end{aligned}
$$

$$
\sum_{i=1}^{n} X_{i} \geq r Q+(\mathrm{i}+1) P u-P T_{d}-P i s t
$$

Equation 11 was established to ensure that the production amount tallied with the total delivery size. Equation 12 was used to ensure that the final shipment quantity tallied with the original production quantity. Equation 13 was established to ensure that the load capacity of the vehicle exceeded or equaled the amount of shipment. Equation 14 was used to illustrate the amount of revenue for a recovery rehabilitation cycle that can meet consumer demand while Equation 15 was used to illustrate the load capacity constraints in the recovery board cycle. Equation 16 was created to ensure that the number of pending orders were not in the negatives (backorders).

\subsection{Data Formulation}

This section presents the data formulation for several experiments to demonstrate the performance and evaluate the stability of the proposed model in this research with respect to varying parameter values. Five different test instances were generated by arbitrarily changing the cost parameters. The $A, B, L$, st, $q t$, and $T d$ parameter values used in this study were adopted from Hishamuddin et al. ${ }^{30,32)}$, which are the base models that we have extended in this study. The parameters of the five test problems are shown in Table 1 . Test 1 was the benchmark test used to adjust the parameter values of subsequent tests. Test 2 was modified where $B$ was raised, while $L$ was lowered. Test 3 had a higher parameter value for $A$. In addition, $H$ was raised in Test 4 , while for Test $5, \mathrm{Td}$ was reduced to a lower value than in Test 1 .

Table 1. Parameters of the five test problems.

\begin{tabular}{|c|c|c|c|c|c|}
\hline Test & U1 & U2 & U3 & U4 & U5 \\
\hline$A$ & 20 & 20 & 30 & 20 & 20 \\
\hline$H$ & 1.2 & 1.2 & 1.2 & 2.4 & 1.2 \\
\hline$P$ & $\begin{array}{c}2500 \\
00\end{array}$ & 250000 & 250000 & 250000 & 250000 \\
\hline$D$ & $\begin{array}{c}2000 \\
00\end{array}$ & 200000 & 200000 & 200000 & 200000 \\
\hline$B$ & 1 & 10 & 1 & 1 & 1 \\
\hline$L$ & 50 & 1 & 50 & 50 & 50 \\
\hline$T d$ & 0.008 & 0.008 & 0.008 & 0.008 & 0.001 \\
\hline$C D$ & 2000 & 2000 & 2000 & 2000 & 2000 \\
\hline$C r$ & 3 & 3 & 3 & 3 & 3 \\
\hline$q t$ & 5000 & 5000 & 5000 & 5000 & 5000 \\
\hline$W$ & 0.006 & 0.0066 & 0.0066 & 0.0066 & 0.0066 \\
\hline$S C$ & 0.000 & 0.00004 & 0.00004 & 0.00004 & 0.00004 \\
\hline$C O 2$ & 150 & 150 & 150 & 150 & 150 \\
\hline$D i$ & 10 & 10 & 10 & 10 & 10 \\
\hline$t i$ & 0.083 & 0.083 & 0.083 & 0.083 & 0.083 \\
\hline$s t$ & 0.000 & 0.00005 & 0.00005 & 0.00005 & 0.00005 \\
7 & 057 & 7 & 7 & 7 & 7 \\
\hline & & & & & \\
\hline
\end{tabular}


As the unique extension of our model is the integration of the refrigeration costs and cost of carbon emissions from this source, suitable parameters from related sources have been added to complement the contribution of our study. The $C D$ parameter values were taken from Cardenas-Barron et al. ${ }^{33)}$. References from Darom et al. ${ }^{11)}$ were used to calculate the $C O 2, P, D$, and $S C$ parameter values, while the $C r$ and $W$ parameter values were adopted from Wang et al. ${ }^{34)}$.

\section{Results and Discussion}

This study is a complex constrained nonlinear programming problem, where the optimal production quantity, $X_{i}$, and recovery cycles, $n$, were defined as the decision variables. LINGO was used to solve the developed mathematical model to obtain optimum results. The constructed mathematical model was coded in LINGO with constraints and errors analysed along with the total cost, TC. The results of this model provide optimum inventory recovery policies for a disruption occurence.

\subsection{Numerical Analysis}

A numerical analysis was conducted based on the data presented in Table 1. The total cost, TC, and the number of recovery cycles, $n$, were determined for each of the test problems. Note that $n$ began at 2 because the software could not account for when the results of $n=1$ due to assumptions and constraints that were set in place to limit the linkage of answers or non-existent answers.

The experimental results for TC and $n$ are presented in Table 2 and plotted in Fig. 2. The TC of each test was high because the cost of lost sales $L$ was high except for U2 where $L$ was low. Based on the results, the optimum number of recovery cycles for U1 was $n=7$ with a $T C$ of $\$ 95975.25$. The TC of U3 was higher than U1 due to an increase in the cost per unit setup, $A$. The optimum number of recovery cycles for U3 was $n=6$ with a TC of $\$ 117130.5$. The optimum number of recovery cycles for U4 was $n=8$ with a $T C$ of $\$ 80756.98$ as the high annual inventory holding cost $H$ increased TC.

U5 had the lowest $T C$ as the duration of disruption $T d$ was low, enabling it to recover faster over a shorter period of time. As such, the optimum number of recovery cycles for U5 was $n=5$ with a TC of $\$ 71671.29$.

Table 2. Tests and total number of recovery cycles $n$.

\begin{tabular}{|c|c|c|c|c|c|}
\hline $\boldsymbol{n}$ & $\mathbf{U 1}$ & $\mathbf{U} 2$ & $\mathbf{U 3}$ & $\mathbf{U 4}$ & $\mathbf{U 5}$ \\
\hline \multirow{2}{*}{2} & 195215. & 18468.7 & 218036. & 165563. & 114741. \\
& 9 & 4 & 9 & 8 & 1 \\
\hline \multirow{2}{*}{3} & 174719. & 21696.8 & 192759. & 151366. & 94229.2 \\
& 8 & 9 & 7 & 1 & 6 \\
\hline \multirow{2}{*}{4} & 154250. & 24974.3 & 167519. & 137204. & 73737.6 \\
& 3 & 5 & 9 & 0 & 4 \\
\hline 5 & 133805. & 28283.7 & 142310. & 123044. & 71671.2 \\
\hline
\end{tabular}

\begin{tabular}{|c|c|c|c|c|c|}
\hline & 8 & 3 & 6 & 6 & 9 \\
\hline \multirow{2}{*}{6} & 113378. & 31619.1 & 117130. & 108946. & 83732.9 \\
& 4 & 1 & 5 & 4 & 4 \\
\hline \multirow{2}{*}{7} & 95975.2 & 34977.9 & 117339. & 94811.5 & 95811.3 \\
& 5 & 5 & 2 & 3 & 1 \\
\hline \multirow{2}{*}{8} & 108099. & 38358.9 & 132173. & 80756.9 & 107915. \\
& 9 & 5 & 8 & 8 & 6 \\
\hline \multirow{2}{*}{9} & 120240. & 41761.3 & 147039. & 86123.1 & 120037. \\
& 4 & 9 & 7 & 7 & 2 \\
\hline 1 & 132401. & 45184.8 & 161934. & 94894.0 & 132179. \\
0 & 8 & 4 & 2 & 4 & 7 \\
\hline \hline
\end{tabular}

\section{TC vs $n$}

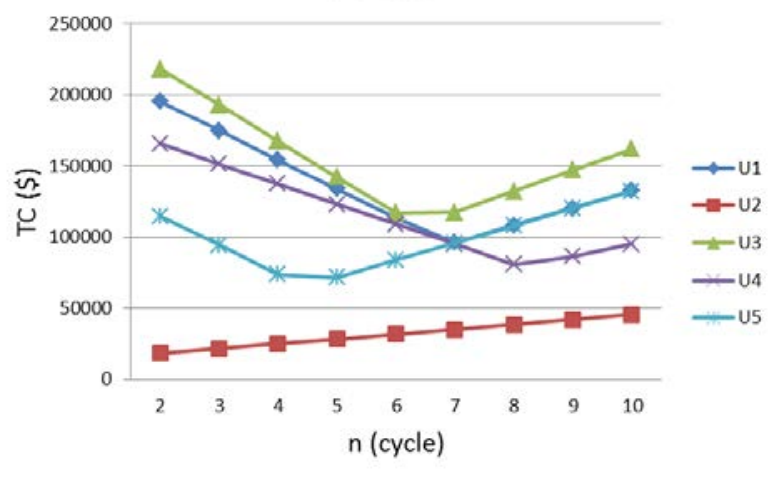

Fig. 2: $T C$ with respect to $n$.

In addition, a sensitivity analysis was performed to test the stability of the developed model. Selected parameters were varied to investigate its effect on total costs. Fig. 3 shows that the effect of increasing the cost of lost sales $L$ when the cost of backorders is fixed at $B=\$ 1$. It was observed that when $L$ increased from $\$ 5$ to $\$ 65$, the backorder quantity $B O Q$ increased while the lost sales quantity LSQ decreased to zero.

The duration of disruption $T d$ was fixed between 0.001 to 0.01 minutes. The total cost TC was found to increase as $T d$ increased. Additionally, when $T d$ increased, the number of recovery cycles, $n$, also increased as $T d$ is very closely related to $n$ (Fig. 4). Furthermore, it can be seen that the amount of carbon dioxide released increases as the distance traveled by the vehicle, $D i$, increases, thereby, affecting the environment. Therefore, frequent disruptions will significantly affect the sustainability of the environment, as well as increase the total recovery costs (Fig. 5).

TC was found to decrease as the load capacity of the vehicle, $q$ t, increased over a period of time (Fig. 6). Vehicles that ship with higher capacities have lower transmission frequencies. Therefore, carbon output from the vehicle and its cooling system can be decreased during disruptions, as carbon output depends on the vehicle's load capacity. This indicates that $T C$ can be reduced by optimising truck capacity usage in the recovery phase to preserve the environment, while minimising recovery costs. 


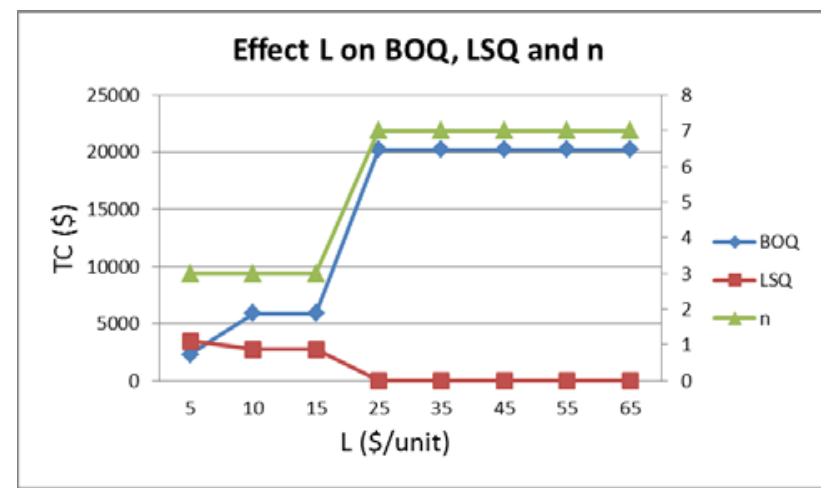

Fig. 3: The effect of $L$ on $B O Q, L S Q$, and $n$.

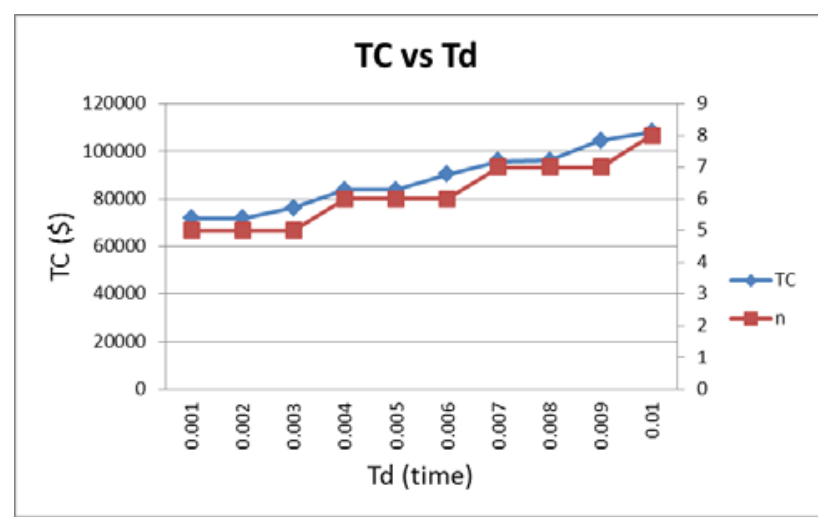

Fig. 4: $T C$ with respect to $T d$.

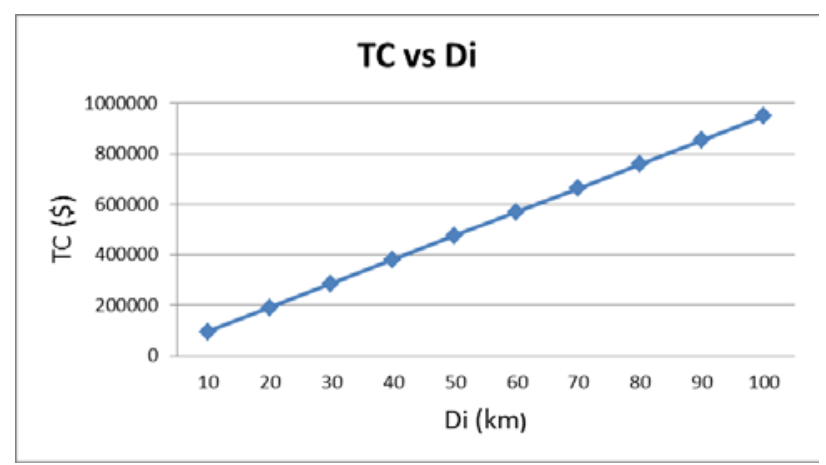

Fig. 5: $T C$ with respect to $D i$.

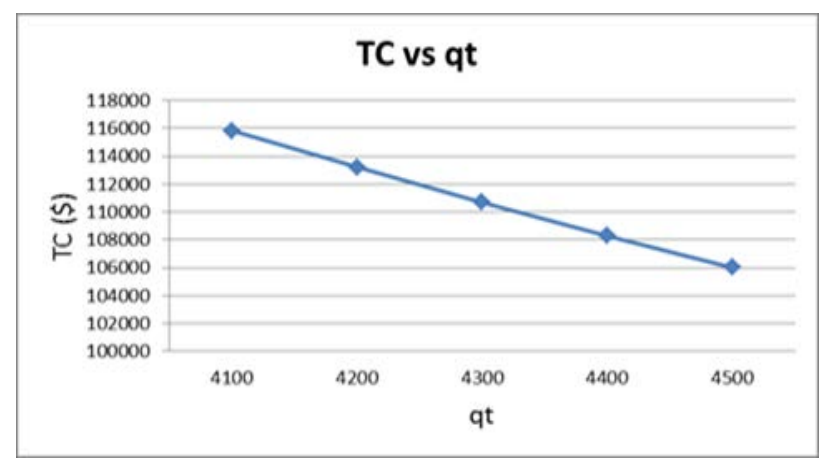

Fig. 6: $T C$ with respect to $q$ t.

\subsection{Case Study}

In this work, a case study was performed to illustrate applicability of the developed model to a real-world scenario. Particularly, the model was applied to the logistics operation of a selected company to seek the optimal decision of recovery costs in the event of a disruption. Supply chain data was collected from an ice factory named Company $\mathrm{X}$, which produces ice and delivers it within Selangor as well as Semenyih, Hulu Langat, and Cheras.

Of the 23 lorries under Company $\mathrm{X}$, only five participated in our study. Each of the five lorries carried and delivered varying quantities of ice to designated location as per customer requests. Therefore, while the make and model of the lorries were identical, the distances travelled, Di and capacities carried, qt varied. Table 3 shows the distances travelled and load capacities carried by the five lorries in a day.

Table 3. Lorry delivery data.

\begin{tabular}{clccc}
\hline Lorry & Destination & $\begin{array}{c}\text { Travel } \\
\text { Distance } \\
(\mathrm{km})\end{array}$ & Units & $\begin{array}{c}\text { Capacity } \\
(\mathrm{kg})\end{array}$ \\
\hline Lorry A & Sg. Ramal & 25 & 281 & 1124 \\
Lorry B & Cheras & 42 & 290 & 1160 \\
Lorry C & Semenyih & 35 & 366 & 1464 \\
Lorry D & Salak & 50 & 328 & 1312 \\
& Tinggi & & & \\
Lorry E & Hulu & 25 & 381 & 1525 \\
& Langat & & & \\
\hline
\end{tabular}

Table 4. Research parameters.

\begin{tabular}{cc}
\hline Parameter & Value \\
\hline$A$ & 2.5 \\
$H$ & 3.0 \\
$B$ & 10 \\
$D$ & 604000 \\
$L$ & 70 \\
$P$ & 750000 \\
$T d$ & 0.0008 \\
$s t$ & 0.0006 \\
\hline
\end{tabular}

As each unit of ice package weighed $4 \mathrm{~kg}$, the total number of units of ice package was multiplied by $k=4 \mathrm{~kg}$ to determine the load capacity ( $q t$ ) carried by each lorry in kilograms. Carbon emission were calculated using EURO's predetermined range of EURO $2=175 \mathrm{~g} / \mathrm{km}$. LINGO was then utilised to determine the TC of each lorry using the data stated in Table 4.

The total cost, from TC1 to TC8, of each of the five participating lorries is shown in Table 5. Lorry E had the lowest Min TC (\$214321.8) although it carried the heaviest load qt compared to other lorries. Lorry D had the highest Min TC (\$558022.9) of the five lorries, followed by Lorry B (\$552970.1), Lorry C (\$438969.2), and Lorry A (\$421116.4).

Based on Table 3, although Lorries A and E traveled the same distance $(25 \mathrm{~km})$, they each carried different load capacities with Lorry E carrying 1525 kg and Lorry A carrying only $1124 \mathrm{~kg}$. This was because capacity maximisation reduces TC. The cooling cost of both lorries 
were the same as both lorries took the same amount of time to reach their delivery destinations, however, the carbon cost of Lorry E (\$1761.441) was higher than that of Lorry A (\$1298.269) as Lorry E carried a heavier load (1525 kg). Lorry D had the highest TC as it traveled the longest distance $(50 \mathrm{~km})$ compared to the other four lorries (25 km to $42 \mathrm{~km}$ ).

Table 5. Total cost of each vehicle.

\begin{tabular}{|c|c|c|c|c|c|}
\hline $\begin{array}{c}\text { TC } \\
\text { Cost } \\
\end{array}$ & Lorry A & Lorry B & Lorry C & $\begin{array}{c}\text { Lorry } \\
\text { D } \\
\end{array}$ & Lorry E \\
\hline TC1 & 15 & 15 & 15 & 15 & 15 \\
\hline \multirow{2}{*}{ TC2 } & 13.242 & 3.5396 & 11.479 & 3.5396 & 12.028 \\
\hline & 84 & 03 & 32 & 86 & 38 \\
\hline \multirow{2}{*}{ TC3 } & 190.43 & 25.713 & 203.38 & 25.713 & 189.28 \\
\hline & 27 & 89 & 82 & 81 & 04 \\
\hline TC4 & 195756 & $\begin{array}{c}469574 \\
.3\end{array}$ & 195756 & $\begin{array}{c}469574 \\
.3\end{array}$ & 195756 \\
\hline TC5 & 45 & 45 & 45 & 45 & 45 \\
\hline TC6 & $\begin{array}{c}223742 \\
.1\end{array}$ & $\begin{array}{c}80961 . \\
08\end{array}$ & $\begin{array}{c}240492 \\
.2\end{array}$ & $\begin{array}{c}85216 . \\
01\end{array}$ & 164909 \\
\hline TC7 & 56.25 & 94.5 & 78.75 & 112.5 & 56.25 \\
\hline \multirow{2}{*}{ TC8 } & 1298.2 & 2250.9 & 2367.3 & 3030.8 & 1761.4 \\
\hline & 69 & 49 & 77 & 34 & 41 \\
\hline Min & 421116. & 552970 & 438969 & 558022 & 214321 \\
\hline$T C$ & 4 & .1 & .2 & .9 & .8 \\
\hline
\end{tabular}

It was determined that $T C$ is closely related to the transportation cost and the load capacity of each lorry. Therefore, it is advisable to deliver goods to a destination when lorries are carrying their maximum capacities as it reduces the frequency of lorries shipped on a route. This simultaneously reduces not only transportation cost, but indirectly reduces the cooling and carbon cost as well. The effect of a long period disruption can be reduced by delivering products using lorries with larger load capacities.

Based on the results provided by LINGO, cooling and carbon costs also contribute to an increase in total optimum costs (Min TC). As seen in Fig. 7, cooling cost is closely related to travel distance.

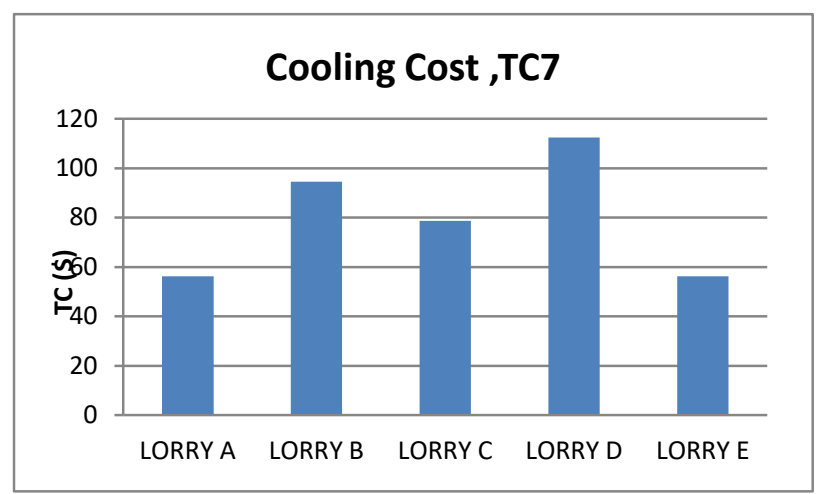

Fig. 7: Cooling cost of each lorry.
Lorry D had the highest cooling cost as it travelled the longest distance $(50 \mathrm{~km})$ while Lorries A and $\mathrm{E}$ had the lowest cooling costs as they travelled the shortest distance (25 km).

Fig. 8 shows that carbon costs is closely related to travel distance and load capacity. Lorry D had the highest carbon cost $(\$ 3030,834)$ as it travelled the longest distance. As carbon costs is also influenced by load capacity, Lorry E had a higher carbon costs than Lorry A as Lorry E carried a heavier load. As cooling and carbon costs have a linear effect on the total recovery costs incurred by the company, hence, it is crucial to identify the shortest distance and the optimum truck capacity for each shipment schedule to minimise the total cost of recovery in the face of disruptions. This will in turn reduce the adverse effects of cold chain disruptions to the environment, and ultimately help preserve environmental sustainability in the long run.

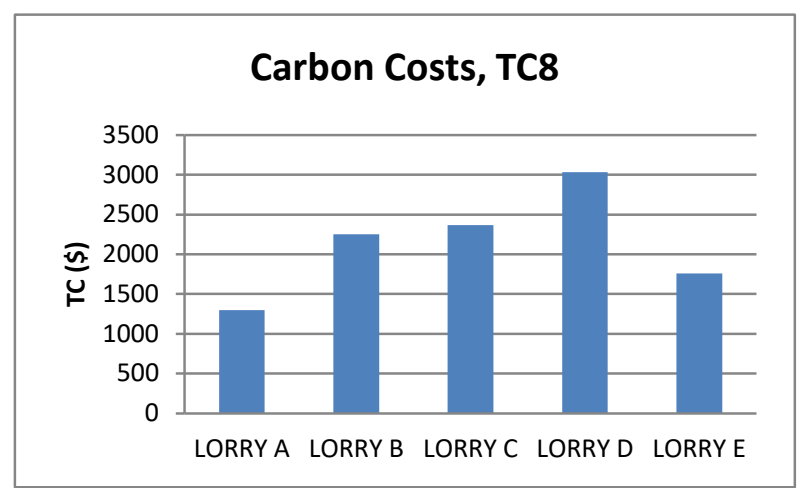

Fig. 8: Carbon costs of each lorry.

\section{Conclusion}

Transportation disruptions are interruptions that delay deliveries and deviate the supply chain system from the stipulated delivery schedule. As such, not only is product quality affected but these disruptions in transportation also affect the environment, as logistics activity is known as the main contributor to carbon footprint in the supply chain. In this work, the effect of transportation disruption on the cold chain system has been studied. This study developed a single-stage inventory model to illustrate the problem of a cold chain system subject to transportation disruption. By solving the developed mathematical model, the new recovery schedule and costs involved in the recovery schedule of the cold chain can be determined.

The results show that truck capacity has a significant effect on recovery costs, where a larger truck capacity is able to reduce delivery frequency, hence lowering the transportation related costs as well as carbon emissions from the fuel consumption and refrigeration system. In conclusion, this study proved that the operational decisions of the cold chain can be optimised to assist in reducing carbon footprint, especially during unexpected disruptions in the supply chain.

An interesting extension of this study would be to integrate the vehicle routing problem into the model to 
analyse the effect of using different routes to the optimal solution and total recovery costs. Additionally, incorporating the time factor and constraint for perishable goods would be another worthwhile extension to be explored. In conclusion, the developed optimisation tool is a useful method to assist decision makers on the optimal production and delivery decisions to minimize overall cold chain costs, thereby reducing carbon emissions and sustaining the environment.

\section{Acknowledgements}

The authors would like to thank the Ministry of Higher Education Malaysia and Universiti Kebangsaan Malaysia for their support under the research university grant GUP2018-100.

\section{Nomenclature}

A cost of inventory for one cycle (\$ / maintenance)

$D \quad$ demand for each product (unit / year)

$H \quad$ annual inventory holding cost (\$ / unit / year)

$P \quad$ production rate (unit / year)

$Q \quad$ production lot size in original table (unit)

Td duration of disruption (-)

$u$ withdrawal time for normal cycle (maintenance time + idle time) $(\mathrm{T}-(\mathrm{Q} / \mathrm{P})$ )

to beginning of recovery window $(-)$

t1 end of recovery window (-)

$Q \quad$ production cycle time for original cycle $(\mathrm{Q} /$ P)
Di

$S C$

$\mathrm{CO} 2$

$q t$

$k$

$C D$ distance travelled by the vehicle $(\mathrm{km})$ social cost of carbon ( $\$$ / g) carbon footprint of the vehicle $(\mathrm{g} / \mathrm{km})$ load capacity of the vehicle (unit) unit of weight ( 1 unit $=4 \mathrm{~kg}$ ) transportation cost for each delivery ( $\$ /$ distance / unit)

Greek symbols

$\delta$

cycle idle time (-)

\section{References}

1) J. Jouzdani, and K. Govindan, "On the sustainable perishable food supply chain network design: a dairy products case to achieve sustainable development goals,” J. Clean. Prod., 278123060 (2020).

2) M. Pariazar, and M.Y. Sir, "A multi-objective approach for supply chain design considering disruptions impacting supply availability and quality,” Comput. Ind. Eng., 121 113-130 (2018).

3) T. Sawik, "Integrated supply chain scheduling under multi-level disruptions,” IFAC-PapersOnLine, 48 (3) 1515-1520 (2015).

4) K.P. Scheibe, and J. Blackhurst, "Supply chain disruption propagation: a systemic risk and normal accident theory perspective,” Int. J. Prod. Res., 56 (12) 43-59 (2018).

5) M. Song, S. Wang, and R. Fisher, "Transportation, iceberg costs and the adjustment of industrial structure in china," Transp. Res. Part D Transp. Environ., 32 278-286 (2014).

6) L.M. Maiyar, and J.J. Thakkar, "Modelling and analysis of intermodal food grain transportation under hub disruption towards sustainability,” Int. J. Prod. Econ., 217 281-297 (2019).

7) L. Ramundo, M. Taisch, and S. Terzi, "State of the art of technology in the food sector value chain towards the IoT,” in: 2016 IEEE 2nd Int. Forum Res. Technol. Soc. Ind. Leveraging a Better Tomorrow, IEEE, 2016: pp. 1-6.

8) M. Pariazar, S. Root, and M.Y. Sir, "Supply chain design considering correlated failures and inspection in pharmaceutical and food supply chains," Comput. Ind. Eng., 111 123-138 (2017).

9) R. Manzini, and R. Accorsi, "The new conceptual framework for food supply chain assessment," $J$. Food Eng., 115 (2) 251-263 (2013).

10) X. Cai, and $X$. Zhou, "Optimal policies for perishable products when transportation to export market is disrupted," Prod. Oper. Manag., 23 (5) 907-923 (2014).

11) N.A. Darom, H. Hishamuddin, R. Ramli, and Z.M. Nopiah, "An inventory model of supply chain disruption recovery with safety stock and carbon 
emission consideration,” J. Clean. Prod., 197 10111021 (2018).

12) Y. Zhang, F. Rong, and Z. Wang, "Research on cold chain logistic service pricing-based on tripartite stackelberg game,” Neural Comput. Appl., 32 (1) 213-222 (2020).

13) P.S. Taoukis, E. Gogou, T. Tsironi, M. Giannoglou, E. Dermesonlouoglou, and G. Katsaros, "Food cold chain management and optimization,” in: Emerg. Tradit. Technol. Safe, Heal. Qual. Food, Springer, 2016: pp. 285-309.

14) J.R. Montoya-Torres, A. Muñoz-Villamizar, and C.A. Vega-Mejía, "On the impact of collaborative strategies for goods delivery in city logistics," Prod. Plan. Control, 27 (6) 443-455 (2016).

15) H. Akamine, M. Mitsuhara, and M. Nishida, "Developments of coal-fired power plants: microscopy study of fe-ni based heat-resistant alloy for efficiency improvement," Evergr. Jt. J. Nov. Carbon Resour. Sci. Green Asia Strateg., 3 (2) 45-53 (2016).

16) H. Sosiati, Y.A. Shofie, and A.W. Nugroho, “Tensile properties of kenaf/e-glass reinforced hybrid polypropylene (pp) composites with different fiber loading," (2018).

17) B. Shahriari, A. Hassanpoor, A. Navehebrahim, and S. Jafar, "Designing a green human resource management model at university environments: case of universities in tehran,” Evergreen, 7 (3) 336-350 (2020).

18) B. Shahriari, A. Hassanpoor, A. Navehebrahim, and S. Jafarinia, "A systematic review of green human resource1 management,” Environ. Prot., 731 (2019).

19) K. Mehta, and P.K. Chugan, "Green hrm in pursuit of environmentally sustainable business,” Purs. Environ. Sustain. Bus. (June 1, 2015). Univers. J. Ind. Bus. Manag., 3 (3) 74-81 (2015).

20) J. Milliman, "Leading-edge green human resource practices: vital components to advancing environmental sustainability,” Environ. Qual. Manag., 23 (2) 31-45 (2013).

21) M.T. Kibria, M. Islam, B.B. Saha, T. Nakagawa, and S. Mizuno, “Assessment of environmental impact for air-conditioning systems in japan using hfc based refrigerants,” Evergreen, 6 (3) 246-253 (2019).

22) N. Al Theeb, H.J. Smadi, T.H. Al-Hawari, and M.H. Aljarrah, "Optimization of vehicle routing with inventory allocation problems in cold supply chain logistics,” Comput. Ind. Eng., 142106341 (2020).

23) M. Babagolzadeh, A. Shrestha, B. Abbasi, Y. Zhang, A. Woodhead, and A. Zhang, "Sustainable cold supply chain management under demand uncertainty and carbon tax regulation," Transp. Res. Part D Transp. Environ., 80102245 (2020).

24) Y. Esmizadeh, M. Bashiri, H. Jahani, and B. AlmadaLobo, "Cold chain management in hierarchical operational hub networks,” Transp. Res. Part E
Logist. Transp. Rev., 147102202 (2021).

25) Y. Fang, Y. Jiang, L. Sun, and X. Han, "Design of green cold chain networks for imported fresh agriproducts in belt and road development," Sustainability, 10 (5) 1572 (2018).

26) A.K. Garside, "An optimization model for cold chain food distribution,” Int. J. Res. Ind. Eng., 8 (3) 243253 (2019).

27) C.-I. Hsu, W.-T. Chen, and W.-J. Wu, “Optimal delivery cycles for joint distribution of multitemperature food," Food Control, 34 (1) 106-114 (2013).

28) C. Wei, W.-W. Gao, Z.-H. Hu, Y.-Q. Yin, and S.-D. Pan, "Assigning customer-dependent travel time limits to routes in a cold-chain inventory routing problem,” Comput. Ind. Eng., 133 275-291 (2019).

29) Y. Ji, H. Yang, and M. Chen, "Logistics network configuration for fresh agricultural products," in: 2017 29th Chinese Control Decis. Conf., IEEE, 2017: pp. 5724-5727.

30) H. Hishamuddin, R.A. Sarker, and D. Essam, “A recovery model for a two-echelon serial supply chain with consideration of transportation disruption," Comput. Ind. Eng., 64 (2) 552-561 (2013).

31) H. Hishamuddin, R.A. Sarker, and D. Essam, “A recovery model for an economic production quantity problem with disruption,” in: 2010 IEEE Int. Conf. Ind. Eng. Eng. Manag., IEEE, 2010: pp. 198-202.

32) H. Hishamuddin, R.A. Sarker, and D. Essam, “A disruption recovery model for a single stage production-inventory system,” Eur. J. Oper. Res., 222 (3) 464-473 (2012).

33) L.E. Cárdenas-Barrón, and S.S. Sana, "Multi-item eoq inventory model in a two-layer supply chain while demand varies with promotional effort," Appl. Math. Model., 39 (21) 6725-6737 (2015).

34) Q. Ma, W. Wang, Y. Peng, and X. Song, “An optimization approach to the intermodal transportation network in fruit cold chain, considering cost, quality degradation and carbon dioxide footprint," Polish Marit. Res., 25 (1) 61-69 (2018). 